\title{
How to size the main aortic endograft in a chimney procedure
}

\author{
Heng-Wen Chou, MD, Chih-Yang Chan, MD, PhD, Shoei-Shen Wang, MD, PhD, and I-Hui Wu, MD, \\ Taipei, Taiwan
}

The application of endovascular aortic repair in difficult circumstances, such as juxtarenal, pararenal, or thoracoabdominal aortic aneurysms, is limited. To address this difficulty, the chimney technique ${ }^{1}$ has been expanded and applied widely. Other than the surgeon's individual experience and preference, however, there is currently no consensus regarding how to choose the appropriate size for the main aortic graft (MAG) parallel to the visceral chimney graft (CG) so that they accommodate each other properly inside the native aorta. Isoperimetric inequality ${ }^{2}$ states that among all closed curves in the plane of a fixed perimeter, a circle maximizes the area of its enclosed region. In this study, we propose a mathematical formula that was based on isoperimetric inequality to select the size of the MAG inside a known diameter of the native aorta and visceral CG:

$$
\mathrm{R}^{\prime} \geq \sqrt{\left(1.44 \mathrm{R}^{2}-\mathrm{r}^{2}\right)}
$$

where $R^{\prime}$ is the radius of the MAG, $R$ is the radius of the native aorta, and $r$ is the radius of the CG.

\section{CLINICAL SUMMARY}

An 80-year-old man was seen with a pulsating abdominal mass. Computed tomographic angiography (CTA) showed a 5.54-cm infrarenal abdominal aortic aneurysm with a short neck about $5.3 \mathrm{~mm}$ in length below the left renal artery (LRA). The diameter of the LRA was $4.9 \mathrm{~mm}$ (Figure 1, $A$ ). The native aortic segment was $24.1 \mathrm{~mm}$ (Figure 1,B), and the chosen LRA Viabahn chimney graft (W.L. Gore \& Associates, Flagstaff, Ariz) was $6 \mathrm{~mm}$. According the equation mentioned previously, the radius of $\mathrm{MAG}\left(\mathrm{R}^{\prime}\right)$ should have been equal to or larger than $\sqrt{(12 \times 12 \times 1.44-3 \times 3)}$, or $14 \mathrm{~mm}$. A $28-\mathrm{mm}$ Excluder bifurcated main body device (W.L. Gore \& Associates) was therefore chosen. The 1-year follow up CTA showed good results with no endoleaks. Blood flow in the

\footnotetext{
From the Department of Surgery, Cardiovascular Division, National Taiwan University Hospital, Taipei, Taiwan.

Disclosures: Authors have nothing to disclose with regard to commercial support.

Received for publication Sept 9, 2013; revisions received Oct 16, 2013; accepted for publication Oct 31, 2013; available ahead of print Dec 11, 2013.

Address for reprints: I-Hui Wu, MD, Department of Surgery, Cardiovascular Section, National Taiwan University Hospital, No. 7, Chung-Shan S Rd, Taipei, Taiwan (E-mail: aaronihuiwu@gmail.com).

J Thorac Cardiovasc Surg 2014;147:1099-101

$0022-5223 / \$ 36.00$

Copyright (c) 2014 by The American Association for Thoracic Surgery

http://dx.doi.org/10.1016/j.jtcvs.2013.10.049
}

left kidney was through the 6-mm CG in the LRA (Figure 1, C).

\section{DISCUSSION}

The chimney technique is designed to lengthen the landing neck and preserve the important aortic branches in complex short-neck aortic aneurysmal cases. One of the long-considered drawbacks of this technique, however, has been the type I endoleak, in which the blood infiltrates into the aneurysmal sac through the gutter between the CG and the MAG. ${ }^{3-5}$ To prevent the type I endoleak, the gutters between the MAG, the CG, and the aortic wall should be as narrow as possible from a geometric aspect. Consequently, accurate diameter estimates of the deployed grafts and the native aorta are of great importance.

In a regular endovascular aortic repair procedure, the stent grafts are usually oversized by $10 \%$ to $20 \%$ relative to the diameter measurements of the native vessels according to CTA. The estimated cross-sectional area of the stent graft is thus 1.21 to 1.44 times larger than the area of the native aorta. If a CG is needed, in ideal circumstances, the total cross-sectional area made by the MAG and the CG should be equal to 1.21 to 1.44 times the cross-sectional area of the native aorta. The radii of the native aorta and chimney vessel are measured preoperatively according to image studies and designated as $R$ and $r$, respectively. The estimated cross-sectional area and perimeter of the MAG are designated as $A$ and $L$ (Figure 2), yielding the following equation:

$$
\begin{aligned}
& 1.44 \pi \mathrm{R}^{2}=\pi \mathrm{r}^{2}+\mathrm{A} \\
& \mathrm{A}=1.44 \pi \mathrm{R}^{2}-\pi \mathrm{r}^{2}
\end{aligned}
$$

According to the isoperimetric inequality ${ }^{2}$ for the length $L$ of a closed curve (the perimeter of the MAG) and the area $A$ of the planar region it encloses (the cross-sectional area made by the MAG), the equations would be as follows:

$$
\begin{gathered}
4 \pi \mathrm{A} \leq \mathrm{L}^{2} \\
\mathrm{~A} \leq \mathrm{L}^{2} / 4 \pi \\
\mathrm{A}=1.44 \pi \mathrm{R}^{2}-\pi \mathrm{r}^{2} \leq \mathrm{L}^{2} / 4 \pi \\
\mathrm{L} \geq 2 \pi \sqrt{\left(1.44 \mathrm{R}^{2}-\mathrm{r}^{2}\right)}
\end{gathered}
$$



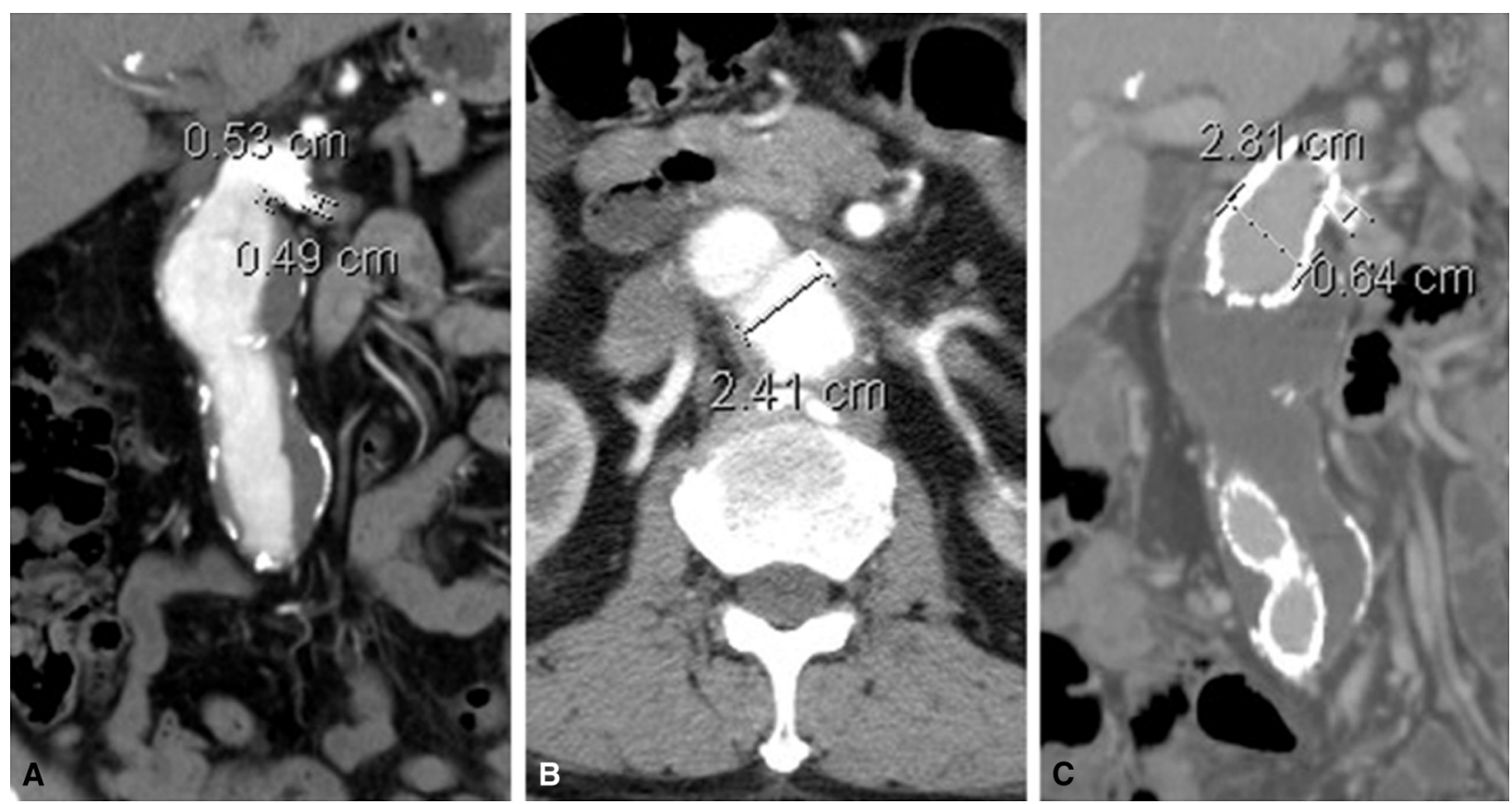

FIGURE 1. A, Preoperative computed tomographic angiography demonstrates a 4.9-mm left renal artery, a 55.4-mm infrarenal abdominal aortic aneurysm, and a 5.3-mm infrarenal neck length below the left renal artery. B, The aortic segment between the left renal artery and right renal artery is $24.1 \mathrm{~mm}$ in width. C, Postoperative computed tomographic angiography demonstrates no endoleak in the aneurysmal sac and a patent 6-mm Viabahn chimney graft to the left renal artery, accommodated with a 28-mm Excluder main body aortic graft.

The MAG is deformed when it is stuffed inside the aorta with the CG; however, the perimeter of the MAG does not change. In addition, $\mathrm{L}=2 \pi \mathrm{R}^{\prime}$, where $R^{\prime}$ stands for the radius of the MAG, yielding the following equation:

$$
\begin{gathered}
\mathrm{L}=2 \pi \mathrm{R}^{\prime} \geq 2 \pi \sqrt{\left(1.44 \mathrm{R}^{2}-\mathrm{r}^{2}\right)} \\
\mathrm{R}^{\prime} \geq \sqrt{\left(1.44 \mathrm{R}^{2}-\mathrm{r}^{2}\right)}
\end{gathered}
$$

From this equation, the radius of the MAG can be estimated. On the basis of this idea, we can also estimate the radius of the main aortic endograft when more than 1 CG is applied:

$$
\mathrm{R}^{\prime} \geq \sqrt{\left(1.44 R^{2}-r_{1}^{2}-r_{2}^{2}-r_{3}^{2} \ldots\right)}
$$

In our model, however, we could only know the low end of the range for the size of the MAG. In our experience, we usually choose the commercialized endograft with the diameter most closely approximating the calculated number from the upper side.

\section{CONCLUSIONS}

In terms of the size selection of the MAG and the CG, our model provides a more scientific way for young surgeons who are not familiar with the chimney technique.
Long-term data are needed, however, before this mathematic formula can be applied widely.

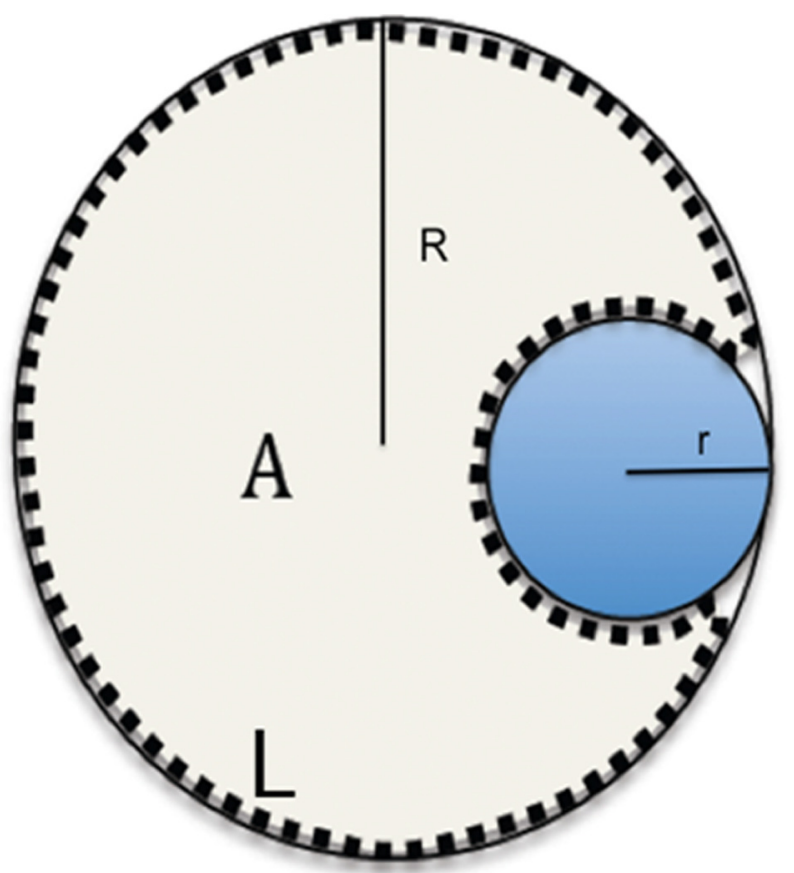

FIGURE 2. Illustration shows the estimated anatomic position of the main aortic and chimney endografts. $R$ represents the radius of the native aorta, $A$ represents the estimated cross-sectional area of the main aortic endograft, $r$ represents the radius of the chimney graft, and $L$ represents the estimated perimeter of the main endograft. 


\section{References}

1. Greenberg RK, Clair D, Srivastava S, Bhandari G, Turc A, Hampton J, et al. Should patients with challenging anatomy be offered endovascular aneurysm repair? J Vasc Surg. 2003;38:990-6.

2. Osserman R. The isoperimetric inequality. Bull Am Math Soc. 1978;84:1182-238.

3. Moulakakis KG, Mylonas SN, Avgerinos E, Papapetrou A, Kakisis JD, Brountzos EN, et al. The chimney graft technique for preserving visceral vessels during endovascular treatment of aortic pathologies. J Vasc Surg. 2012;55: 1497-503.

4. Bruen KJ, Feezor RJ, Daniels MJ, Beck AW, Lee WA. Endovascular chimney technique versus open repair of juxtarenal and suprarenal aneurysms. J Vasc Surg. 2011;53:895-904; discussion 904-5.

5. Greenberg R, Eagleton M, Mastracci T. Branched endografts for thoracoabdominal aneurysms. J Thorac Cardiovasc Surg. 2010;140(6 Suppl):S171-8. 